\title{
Should We Consider Bilirubin When Dosing Troponin in Newborns? Case Report
}

\author{
Valentina Giacchi ${ }^{1 *}$, Carmine Mattia ${ }^{2}$, Pasqua Betta ${ }^{2}$ and Pietro Sciacca ${ }^{3}$ \\ ${ }^{1}$ Department of Pediatrics, AOU Policlinico-Vittorio Emanuele, via Santa Sofia 78 - 95123, Catania, Italy \\ ${ }^{2}$ NICU, AOU Policlinico-Vittorio Emanuele, via Santa Sofia 78 - 95123, Catania, Italy \\ ${ }^{3}$ Pediatric Cardiology, AOU Policlinico-Vittorio Emanuele, via Santa Sofia 78 - 95123, Catania, Italy
}

\begin{abstract}
Background: Troponin is a protein of the troponin-tropomyosin complex in myocardium and it is considered an highly sensitive marker of myocardial necrosis both in adults and newborns with perinatal asphyxia. Some studies assume that high troponin levels in adults without signs of myocardial necrosis could be conditioned by some factors, such as hemolysis, turbidity, and hyperbilirubinemia.

Case presentation: We report a case of a term female newborn of Caucasian race, with high troponin levels in absence of neonatal asphyxia and without clinical or instrumental signs of myocardial ischaemia.

Conclusion: Hyperbilirubinemia might be a factor that could interfere with assessment of sieric troponin T. This might suggest that levels of troponin T should be trusted only when they are associated with signs of other conditions suggesting heart damage or respiratory distress.
\end{abstract}

\section{Publication History:}

Received: February 27, 2015

Accepted: March 20, 2015

Published: March 22, 2015

\section{Keywords:}

Hyperbilirubinemia, Infants, Myocardial damage

\section{Introduction}

Cardiac troponin is a highly specific and very sensitive marker of myocardial necrosis recently used in newborns to rule out a myocardial ischaemia [1]. We report a case of an apparently healthy (except for jaundice) term newborn in which high values of troponin were not related to a documentable myocardial injury.

\section{Case Presentation}

Female baby, born at $40^{\mathrm{a}}$ week by cesarean delivery for lack of commitment, with weight at birth of 3.500 grams, Agar Index 10/10, after physiological pregnancy without needing tocolytic or other therapy in healthy mother. She was fed with formula milk. In third day of life was hospitalized for hyperbilirubinaemia $(18 \mathrm{mg} / \mathrm{dl})$, likely idiopathic, with normal values of AST and ALT (40 U/L and $9 \mathrm{U} / \mathrm{L}$ ) and blood count normal for age (GR 5980000/mmc, Hb $20 \mathrm{~g} / \mathrm{dl}$, Ht 55.9 \%, MCV 93.5 fl, PLT 330000/mmc, GB $14590 / \mathrm{mmc} \mathrm{N} \mathrm{61 \%} \mathrm{L}$ $24,2 \%$ Eo $5,7 \%$ M $6,5 \%)$. We assayed serum values of bilirubin by colorimetric determination and we excluded hereditary hemolytic causes, rhesus or AB0 incompatibility, and metabolic factors. During hospitalization, due to a systolic murmur 2/6 Levine we performed an echocardiography-colordoppler with Philips E33 using S12-4 probe and detected a mild/medium regurgitation of tricuspid valve that is frequent and physiologic in newborns, exspecially in the first days of life, whereas ECG showed only slightly flattened T-wave. We measured the concentration of sieric troponin $\mathrm{T}$ and we found high values: $304.5 \mathrm{pg} / \mathrm{ml}$ in first day, $298 \mathrm{pg} / \mathrm{ml}$ in second day and $286 \mathrm{pg} / \mathrm{ml}$ in third day of hospitalization with the following values of bilirubin: $18 \mathrm{mg} / \mathrm{dl}, 17.1 \mathrm{mg} / \mathrm{dl}$ and $16.4 \mathrm{mg} / \mathrm{dl}$ respectively. This measurement was performed with electrochemiluminescence of high sensitivity troponin T STAT (Short Turnaround Time). Clinic history of the baby didn't show any other signs of heart impairment and concentrations of LDH $(300 \mathrm{U} / \mathrm{L})$, total CK (50 $\mathrm{U} / \mathrm{L}), \mathrm{CK}-\mathrm{MB}(1.2 \mathrm{ng} / \mathrm{ml})$, and myoglobin $(27 \mathrm{ng} / \mathrm{ml})$ were within normal ranges, as well as AST and ALT. Hyperbilirubinaemia was treated by phototherapy until reduction of bilirubin while troponin values decreased $(90 \mathrm{pg} / \mathrm{ml})$, so we could discharge the newborn.

\section{Discussion}

Troponin is an inhibitory protein complex forming part of the contractile apparatus of all striated muscle, including the heart. Specific forms of the three troponin subunits T, C, and I exist in different muscle types [1].

Cardiac troponins are protein components of the troponintropomyosin complex in myocardium. Since troponins do not occur in extracellular space, their appearance in serum is sensitive and specific marker of myocardium damage [2].They start to increase two hours after myocardial infarction or damage, and concentrations can remain raised for up to two weeks after a full thickness infarct [1]. Troponin rising has been described also in other clinical conditions with possible myocardial damage, such as, myocarditis [3], trauma [4], etc: every cardiac troponin value above the 99th percentile of the reference population in the typical clinical setting may be interpreted as myocardial damage with an increase in the risk of major cardiac events [5].

More recently Troponin- $\mathrm{T}$ and troponin-I have been used to identify a cardiac damage also in newborns. Adamcova et al. observed that neonates with in utero exposure to acute or long-term tocolytic therapy by h-sympathicomimetics showed detectable values of cardiac troponins, indicating myocardial damage in these neonates, as well as newborns subjected in utero to magnesium sulphate [6]. Trevisanuto et al. and Distefano et al. in two different studies showed respectively

*Corresponding Author: Dr. Valentina Giacchi, Department of Pediatrics, AOU Policlinico-Vittorio Emanuele, via Santa Sofia 78-95123, Catania, Tel: 393334126158; Fax: 0953782417, Italy; E-mail: valentina.giacchi@yahoo.it

Citation: Giacchi V, Mattia C, Betta P, Sciacca P (2015) Should we consider bilirubin when dosing troponin in newborns? Case Report. Int J Clin Case Stud 1: 101. doi: http://dx.doi.org/10.15344/2455-2356/2015/101

Copyright: (c) 2015 Giacchi et al. This is an open-access article distributed under the terms of the Creative Commons Attribution License, which permits unrestricted use, distribution, and reproduction in any medium, provided the original author and source are credited. 
elevated troponin-T sieric levels and higher troponin-I concentrations in transient myocardial ischemia in preterm newborns with respiratory distress syndrome [7]: infants with severe IRDS have higher levels than infants with moderate IRDS and increased troponin-I serum levels in preterm infants with severe IRDS are explained by myocardial injury or dysfunction due to impaired arterial oxygenation or reduction in cardiac output during treatment with mechanical ventilation $[7,8]$.

In newborns the interpretation of high values is more complicated than in adults [9]. For troponin-I, only two published upper reference limits were found, established with different troponin-I assays [10, 11]. Also, there was no standard procedure to show the distribution of troponin- $\mathrm{T}$ and troponin-I in the neonate reference populations [9].

Clark et al. investigated reference values for troponin- $\mathrm{T}$ in healthy neonates assessing as normal concentration range $10-62 \mathrm{pg} / \mathrm{ml}(0.01-$ $0.062 \mathrm{ng} / \mathrm{ml}$ ), and the 95th centile was $0.153 \mathrm{ng} / \mathrm{ml}$. They assume that the process of birth itself may lead to functional hypoxemia, and that, despite of an apparently uncomplicated delivery; some healthy newborn infants may sustain minimal myocardial injury resulting in a small and probably transient rise in cardiac troponin T. However, the degree of any cardiac dysfunction (if any) is likely to be very mild, without any associated clinical signs or appreciable neonatal morbidity [1]. Baum et al. [9] reported in healthy-termed newborns a higher upper reference limit for troponin-T compared to adults: up to $97 \mathrm{pg} / \mathrm{ml}(0.097 \mu \mathrm{g} / \mathrm{l})$ at 99 th percentile. This circumstance should be considered when interpreting slightly elevated troponin $\mathrm{T}$ levels in newborns, confirming the complexity of evaluating troponin- $\mathrm{T}$.

Serum values of troponin could be influenced by other factors and assay interference led to authentic false positives. Some cases of false high cardiac troponins values have been described and few studies have reported the presence in serum of various interfering substances that can affect analytical procedures (true false positive). The prevalence of true false positives, determined using immunoassay methods, is relatively low, around $0.4 \%$ [12].

Previously Adamcova, researching Troponin T values in 15 healthy term newborns, showed that incidental haemolysis of blood samples can mimic pathological elevation of troponin $\mathrm{T}$ by interfering with the assay [13]. Wenk noticed that when hemolysate was added to plasma, cardiac Troponin I was increased from reference values to high values in a dose-related way. (The manufacturer's interference study was performed by adding high concentration $\mathrm{Hb}$ stock into samples.) [14].

Kwon et al. reported that in 16 adults elevated troponin-I levels were affected by any degree of hemolysis, turbidity, unconjugated hyperbilirubinemia and conjugated hyperbilirubinemia [15]. Masimasi et al. reported a case of a 75-year-old man with chest pain without clear signs of cardiac injury in whom high troponin-I levels were influenced by hyperbilirubinaemia during an episode of intravascular hemolysis [16].

Presence of heterophillic antibodies is particularly known to cause interference in immunoassay. High titers of auto-antibodies and heterophillic antibodies can cause false-positive results with the widely used two-site cardiac Troponin I immunoassays. These antibodies may crosslink with the capture antibodies during the assay. Otherwise, antibody-independent interferences are principally produced by residual fibrin or other micro particles attributable to incomplete separation of serum [17]. Fleming et al. retrospectively assessed 767 patients with suspected myocardial damage and detected
$3.1 \%$ of false high cardiac Troponin I values: $2 \%$ attributed to micro particles or fibrin, and $1 \%$ attributed to heterophilic antibodies. Technical advances with addition of heterophilic antibody blocking agents in immunoassay kits and implementation of repeated assays have decreased the occurrence of false-positive results [18]. McClennen et al. in a large retrospective study of 7305 patients affirmed that falsely elevated cardiac Toponin I results occurred in $0.4 \%$ of cases, mostly caused by micro particles. Rheumatoid factors, a heterogeneous group of auto-antibodies (IgM) directed against immunoglobulin G, are the most frequent cause of cardiac Troponin I false positives [19]. Krahn et al. detected $15 \%$ of false-positive significant values of cardiac Troponin I among patients with positive rheumatoid factors values, that is, approximately $0.75 \%$ of general population and up to $1.5 \%$ of patients with chest pain [20]. The presence of high phosphatase alkaline levels may also interfere with assays [21]. In addition, other factors may interfere with cardiac Troponin I assay results: lipid, auto antibodies, human antimouse antibodies, and heparin [22]. In a study performed by Ungerer et al. to compare 4 contemporary cardiac troponin assays the authors affirmed that the patients with cardiac Troponin $\mathrm{T}$ outliers had significantly lower renal function than those patients with cardiac Troponin I outliers, and this may have contributed to their identification as outliers. A high prevalence (15.9\%) of anti-troponin I and $\mathrm{T}$ antibodies has been reported previously, and it was postulated that these antibodies may potentially cause both positive and negative interference with clinical samples [23].

Michielsen et al. reported a case of a 35-year-old female presenting false positive cardiac Troponin I result caused by a true macrotroponin [24].

Demarchi et al. affirmed that cholecystitis with gallbladder distension can be the sole cause of pathological ECG changes and an increased troponin I level; gallbladder distension reduces coronary blood flow, providing a mechanism for the association of gallbladder disease, myocardial ischemia and ST segment ECG changes. Various sources have also reported elevated troponin levels in patients with sepsis, septic shock or systemic inflammatory response syndrome, but the mechanism by which infection causes troponin release is not yet understood [25].

Makaryus et al. showed that other sources of circulating antibodies include immunotherapies, vaccinations, or blood transfusions may interfere with these immunoassays as well. They examined the case of a 48-year-old man with a history of hypercholesterolemia and obesity who presented with chest pain and was found to have elevated Troponin I levels on two separate occasions. Further work-up revealed that the Troponin I levels were spuriously elevated because the patient's blood revealed a normal cardiac Troponin I level when mixed with polyethylene glycol to inactivate any antibodies interfering with the cardiac Troponin I assay [26].

In our case we found elevated troponin- $T$ values in a baby affected by neonatal icterus, in absence of clinical evident cardiac damage and of other conditions of false positive troponin levels. A false increase of troponin values, as already described in adults, could be due to the hyperbilirubinemia and in this baby the values of troponin were probably hardly conditioned by a paraphysiological state such as the neonatal icterus. In fact we excluded all other causes of false positive high troponin values that we described above and once hyperbilirubinaemia was treated, we documented a contemporary normalization of both bilirubin and troponin blood levels. 
Citation: Giacchi V, Mattia C, Betta P, Sciacca P (2015) Should we consider bilirubin when dosing troponin in newborns? Case Report. Int J Clin Case Stud 1: 101. doi: http://dx.doi.org/10.15344/2455-2356/2015/101

Page 3 of 3

\section{Conclusion}

Persistent high values of troponin T might be found in newborns with perinatal asphyxia and are usually considered as a sign of myocardial injury that may be related both to cardiopulmonary and neurological outcome. Undoubtedly, high levels of troponin T should be trusted only when they are associated with signs of other conditions suggesting heart damage or respiratory distress. In fact we cannot exclude factors out of myocardial injury that could interfere with assessment of serum troponin $\mathrm{T}$, such as hyperbilirubinaemia. This should limit the use of troponin $\mathrm{T}$ in neonatal period only in patients with clear signs of cardiopulmonary impairment as an extremely useful index of myocardial sufferance evolution. This case also suggests that the evaluation of at least two myocardial damage markers simultaneously would detect false positive troponin elevation results and could avoid mistakes in diagnosis. Furthermore, in case of high troponin values in newborns, we advise to exclude hyperbilirubinemia as cause of false positivity since this one is very common in neonatology.

\section{Competing Interests}

The authors report no conflict of interests.

\section{Acknowledgement}

We gratefully acknowledge our clinical laboratory, AOU PoliclinicoVittorio Emanuele, via Santa Sofia 78 -95123 Catania (Italy), for his collaboration and for giving us necessary data.

\section{References}

1. Clark S, Newland P, Yoxalla C, Subhedar N (2004) Concentrations of cardiac troponin $\mathrm{T}$ in neonates with and without respiratory distress. Arch Dis Child Fetal Neonatal Ed 89: F348-F352.

2. Solnica B (2004) Cardiac troponins. Medycyna Praktyczna 10: 133-136.

3. Soongswang J, Durongpisitkul K, Ratanarapee S, Leowattana W, Nana A, et al. (2002) Cardiac troponin T: its role in the diagnosis of clinically suspected acute myocarditis and chronic dilated cardiomyopathy in children. Pediatr Cardiol 23: 531-535.

4. Ferjani M, Droc G, Dreux S, Arthaud M, Goarin JP, et al. (1997) Circulating cardiac troponin $\mathrm{T}$ in myocardial contusion. Chest 111: 427-433.

5. Alpert JS, Thygesen K, Antman E, Bassand JP (2000) Myocardial infarction redefined-A consensus document of The Joint European Society of Cardiology/American College of Cardiology Committee for the redefinition of myocardial infarction. J Am Coll Cardiol 36: 959-969.

6. Adamcova M, Kokstein Z, Palicka V, Vavrov a J, Kostal M, et al. (1999) Cardiac troponin $\mathrm{T}$ in pregnant women having intravenous tocolytic therapy. Arch Gynecol Obstet 262: 121-126.

7. Trevisanuto D, Zaninotto M, Altinier S, Plebani M, Zanardo V (2000) High serum cardiac troponin $T$ concentrations in preterm infants with respiratory distress syndrome. Acta Paediatr 89: 1134-1136.

8. Distefano G, Sciacca P, Mattia C, Betta P, Falsaperla R, et al. (2006) Troponin I as a biomarker of cardiac injury in neonates with idiopathic respiratory distress. Am J Perinatol 23: 229-232.

9. Baum H, Hinze A, Bartels P, Neumeier D (2004) Reference values for cardiac troponins T and I in healthy neonates. Clin Biochem 37: 1079-1082.

10. Shelton SD, Fouse BL, Holleman CM, Sedor FA, Herbert WN (2002) Cardiac troponin I levels in umbilical cord blood. Am J Obstet Gynecol 77: 239-241.

11. Soldin SJ, Murthy JN, Agarwalla PK, Ojeifo O, Chea J (1999) Pediatric reference ranges for creatine kinase, CKMB, Troponin I, iron, and cortisol. Clin Biochem 32: 77-80.

12. Dupont J, Fromonot J, Franceschi F, Deharo JC, Boucraut J, et Al. (2013) A case of false positive troponin elevation: Role of the biological laboratory. Int J Cardiol 162: e66-e67.
13. Adamcova M, Kokstein Z, Palicka V, Podholova M, Kostal M (1995) Troponin $T$ levels in the cord blood of healthy term neonates. Physiol Res 44: $99-104$

14. Wenk RE (1998) Mechanism of Interference by Hemolysis in Immunoassays and Requirements for Sample Quality. Clinical Chemistry 44: 2554.

15. Kwon HJ, Seo EJ, Min KO (2003) The influence of hemolysis, turbidity and icterus on the measurements of CK-MB, troponin I and mioglobina. Clin Chem Lab Med 41: 360-364.

16. Masimasi N, Means RT Jr. (2005) Elevated troponin levels associated with hemolysis. Am J Med Sci 330: 201-203.

17. Zhu Y, Jenkins MM, Brass DA, Ravago PG, Horne BD, et al. (2008) Heterophilic antibody interference in an ultra sensitive 3 site sandwich troponin I immunoassay. Clin Chim Acta 395: 181-182.

18. Fleming SM, O'Byrne L, Finn J, Grimes H, Daly KM (2002) False-positive cardiac troponin I in a routine clinical population. Am J Cardiol 89: 12121215.

19. McClennen S, Halamka JD, Horowitz GL, Kannam JP, Ho KK (2003) Clinical prevalence and ramifications of false-positive cardiac troponin I elevations from the Abbott AxSYM Analyzer. Am J Cardiol 91: 1125-1127.

20. Krahn J, Parry DM, Leroux M, Dalton J (1999) High percentage of false positive cardiac troponin I results in patients with rheumatic factor. Clin Biochem 32: 477-480.

21. Dasgupta A, Chow L, Wells A, Datta P (2001) Effects of elevated concentration of alkaline phosphatase on cardiac troponin I assays. J Clin Lab Anal 15: 175-177.

22. Lin CT, Lee HC, Voon WC, Yen HW, Tang MH, et al. (2006) Positive interference from contrast media in Cardiac troponin i immunoassays. Kaohsiung J Med Sci 22: 107-113.

23. Ungerer JP, Marquart L, O'Rourke PK, Wilgen U, Pretorius CJ (2012) Concordance, Variance, and Outliers in 4 Contemporary Cardiac Troponin Assays: Implications for Harmonization. Clin Chem 58: 274-283.

24. Michielsen EC, Bisschops PG, Janssen MJ (2011) False positive troponin result caused by a true macrotroponin. Clin Chem Lab Med 49: 923-925.

25. Demarchi MS, Regusci L, Fasolini F (2012) Electrocardiographic Changes and False-Positive troponin I in a Patient with Acute Cholecystitis. Case Rep Gastroenterol 6: 410-414.

26. Makaryus AN, Makaryus MN, Hassid B (2007) Falsely elevated cardiac troponin I levels. Clin Cardiol 30: 92-94. 